\title{
Equipes de referência: arranjo institucional para potencializar a colaboração entre disciplinas e profissões
}
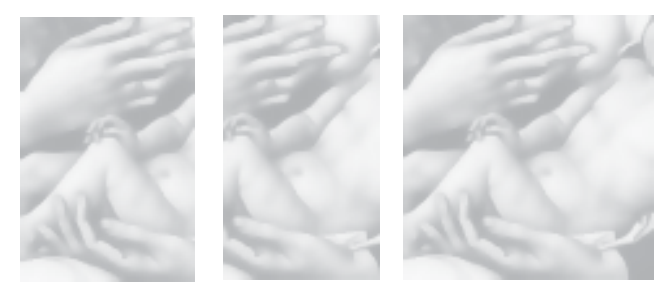

Juarez Pereira Furtado ${ }^{1}$

FURTADO, J.P. Reference teams: an institutional arrangement for leveraging collaboration between disciplines and professions. Interface - Comunic., Saúde, Educ., v.11, n.22, p.239-5, mai/ago 2007.

The need to increase collaboration between disciplines and professions is often stressed in different texts and suggested as a possible solution to the many impasses and issues that teams working in health and education programs and services face. However, the discussion on disciplinary and professional interaction has failed to advance in relation to what was introduced in Brazil in the 70s. On the other hand, the Brasilian Health System (SUS) needs proposals that actually make the integration of knowledge and practice viable in the field of services. This article critiques the dominant notion of interdisciplinary and inter-professional collaboration and suggests that services be organized based on reference teams as a way to encourage and increase collaboration between disciplines and professions.

KEY WORDS: Interdisciplinarity and health. Health services. Service organization and administration. Collective health. Health planning.

A necessidade de mais colaboração entre disciplinas e profissões é freqüentemente ressaltada em diferentes textos $e$ apontada como possível solução para diversos impasses e questões vividas pelas equipes que atuam em programas e serviços dos setores saúde e educação. No entanto, a discussão sobre a interação disciplinar e profissional tem carecido de avanços em relação ao que foi proposto por Japiassu no Brasil dos anos 1970. Por outro lado, o Sistema Nacional de Saúde (SUS) necessita de propostas que, efetivamente, operacionalizem a integração entre saberes e práticas no âmbito dos serviços. No presente artigo, apresentamos algumas críticas à concepção dominante de colaboração interdisciplinar e interprofissional e apontamos a organização de serviços com base em equipes de referência como forma de estimular e aumentar a colaboração entre disciplinas e profissões.

PALAVRAS-CHAVE: Interdisciplinaridade e saúde. Serviços de saúde. Organização e administração de serviços. Saúde coletiva. Planejamento em saúde.

\footnotetext{
${ }^{1}$ Fisioterapeuta; doutor em Saúde Coletiva; membro, Grupo de Estudos "Saúde Coletiva e Saúde Mental: Interfaces", departamento de Medicina Preventiva e Social, Faculdade de Ciências Médicas, Universidade Estadual de Campinas; professor, Universidade Federal de São Paulo, campus Santos. Santos, SP. <juarezpfurtado@hotmail.com>
} 
FURTADO, J.P.

\section{Introdução}

Qualquer um de nós que tenha se aproximado desse tema, já leu ou viu citação do livro "Interdisciplinaridade e patologia do saber", do filósofo Hilton Japiassu, lançado em 1976. Esse texto constitui um marco da introdução do tema em nosso país, tendo sido prefaciado por Georges Gusdorf, pioneiro na sistematização de trabalhos interdisciplinares na Europa, no início da década de 1970. Resultado de seu doutorado um ano antes em Paris, o livro de Japiassu representou a referência mais citada em estudos epistemológicos sobre o tema. Compartilhando boa parte das idéias desse autor, Fazenda (2002, 2001) desenvolveu vários estudos sobre interdisciplinaridade na educação ao longo das últimas décadas. Juntos, os dois autores se constituíram referência obrigatória sobre o tema no Brasil, seja para reiterar ou contrapor suas idéias.

$\mathrm{Na}$ maioria dos textos sobre inter e transdisciplinaridade, encontramos um certo consenso a respeito da idéia de que a especialização fracassou, que urge a recomposição dos fragmentos do saber e que precisamos superar as barreiras edificadas em torno de diferentes áreas do conhecimento (Random, 2000; Morin, 1999; Nunes, 1995). Escritores como Gusdorf (1990) já compararam o conhecimento a uma granada que explodiu em múltiplos pedaços, cada um formando o que chamamos de disciplina. Seria difícil se contrapor a esses argumentos: afinal, constatamos diariamente os limites inerentes aos diversos recortes que fazemos para entender melhor a realidade que nos cerca. Além disso, do ponto de vista subjetivo, quem de nós não guarda alguma nostalgia de um tempo de maior fusão com o mundo, de continuidade entre sensações e pensamentos, de quando tudo parecia integrado e transitável?

Conforme a perspectiva epistemológica, da ciência, disciplinas nada mais são do que um saber organizado, constituído por um conjunto de teorias, conceitos e métodos voltados para melhor compreensão de fenômenos. Ou seja, são territórios do saber que possuem objetos e formas específicas de concebê-lo e dele se aproximar. Segundo a perspectiva pedagógica, disciplinas adquirem sentido de conhecimentos a serem abordados por meio de matérias específicas.

Algum grau de interação entre disciplinas próximas sempre acontece, porém a forma $e$ intensidade desse intercâmbio podem variar significativamente. Na tentativa de caracterizar melhor as diferentes formas de aproximação e trocas entre saberes e disciplinas, alguns autores elaboraram conceitos delineando os modos de interação disciplinar, fixandoos em algum ponto entre dois pólos: por um lado, quase nenhum contato entre as disciplinas, $e$, no outro extremo, grande intercâmbio entre elas. Assim, teríamos a multidisciplinaridade, a pluridisciplinaridade, a interdisciplinaridade e a transdisciplinaridade, que representariam, respectivamente, graus cada vez maiores de interação e troca entre universos disciplinares distintos. Essa classificação, proposta por Jantsch em 1972 (Almeida Filho, 1997), é a mais comumente utilizada, adaptada e desenvolvida por vários estudiosos do assunto, encontrando-se graficamente representada na Figura 1. 


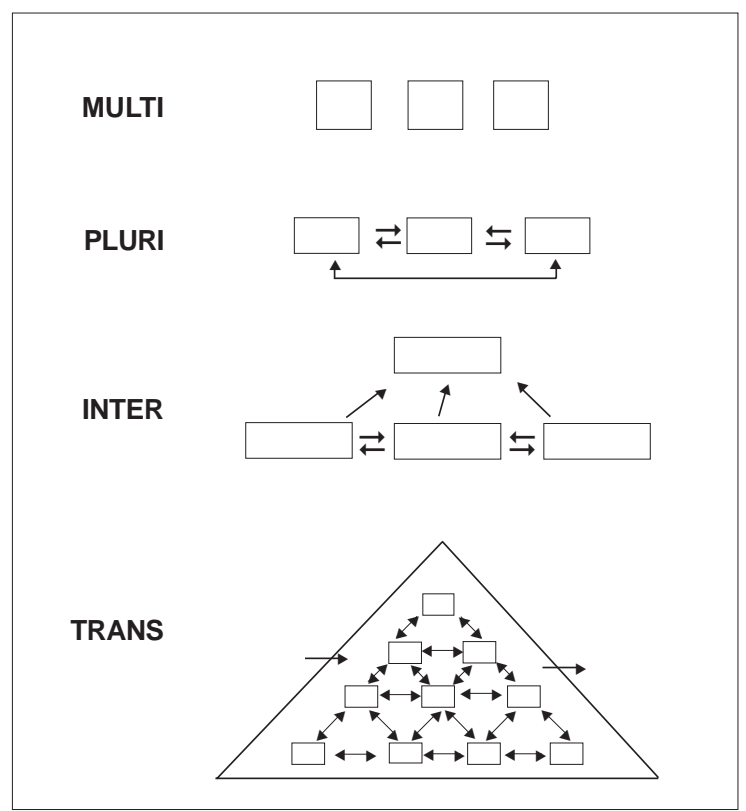

Figura 1. O modelo de Jantsch (adaptado de Silva, 2001, p.4)

A multidisciplinaridade é caracterizada pela justaposição de várias disciplinas em torno de um mesmo tema ou problema, sem o estabelecimento de relações entre os profissionais representantes de cada área no plano técnico ou científico. As várias disciplinas são colocadas lado a lado, carecendo de iniciativas entre si e de organização institucional que estimule e garanta o trânsito entre elas. O funcionamento isolado das diferentes faculdades dentro de uma mesma universidade, o pequeno número de iniciativas conjuntas entre departamentos de uma mesma faculdade, e os quase inexistentes canais de troca entre profissionais que trabalham em um ambulatório de especialidades são boas ilustrações do que vimos discorrendo sobre multidisciplinaridade: as diferentes áreas coexistem lado a lado, porém com baixíssima inter-relação.

A pluridisciplinaridade é caracterizada pelo efetivo relacionamento de disciplinas entre si, havendo coordenação por parte de uma dentre as disciplinas ou pela direção da organização. Nesse caso, são estabelecidos objetivos comuns entre as disciplinas, que deverão estabelecer estratégias de cooperação para atingi-lo. Aqui prevalece a idéia de complementaridade sobre a noção de integração de teorias e métodos, ou seja, opera-se muito mais com a concepção de que uma área do saber deve preencher eventuais lacunas da outra. Mesas-redondas constituídas de especialistas convidados a debater sobre um tema são exemplos de iniciativas pluridisciplinares. Nesses casos, a "síntese" ficará sempre a cargo dos ouvintes. Outro exemplo de interação pluridisciplinar sãos as reuniões tradicionais de discussão de casos, feitas entre membros de categorias profissionais que trabalham em determinada enfermaria de um hospital. 
A interdisciplinaridade representa o grau mais avançado de relação entre disciplinas, se considerarmos o critério de real entrosamento entre elas. Nesse caso, seriam estabelecidas relações menos verticais entre diferentes disciplinas, que passariam, também, a compartilhar uma mesma plataforma de trabalho, operando sob conceitos em comum e esforçando-se para decodificar o seu jargão para os novos colegas. Deve-se perceber que, aqui, não há simples justaposição ou complementaridade entre os elementos disciplinares, mas uma nova combinação de elementos internos e o estabelecimento de canais de trocas entre os campos em torno de uma tarefa a ser desempenhada conjuntamente. Espera-se que daí surjam novos conhecimentos e posturas dos pesquisadores envolvidos. Um bom exemplo de interdisciplinaridade pode ser encontrado na chamada "saúde mental", entendida como resultado da convergência da psiquiatria, psicologia, psicanálise, sociologia e saúde coletiva e operada pelas iniciativas desenvolvidas nos serviços comunitários de atenção aos doentes mentais graves.

Transdisciplinaridade é um termo cunhado por Jean Piaget durante encontro promovido, em 1970, pela Organização de Cooperação e Desenvolvimento Econômico de Países Desenvolvidos (OCDE), em Nice, França, para discutir o tema da interdisciplinaridade. Nesse evento, Piaget afirmou que aos trabalhos interdisciplinares deveriam suceder uma etapa superior, na qual as interações entre o conhecimento se dariam sem as fronteiras disciplinares. Para alguns autores (Fazenda, 2001), esse termo seria um horizonte inalcançável, tendo como função o direcionamento do caminho, tensionando os esforços em busca de modos de entrosamento mais profundos entre campos disciplinares. Outros autores consideram a transdisciplinaridade a única forma realmente válida de interação e um modo efetivo de superar as limitações da interdisciplinaridade (Silva, 2006).

Mais recentemente, Silva (2006) elaborou uma revisão do modelo proposto por Jantsch que nos parece particularmente interessante, por estabelecer avanços em relação aos conceitos que vimos apresentando (Figura 2). Para o autor, na perspectiva unidisciplinar, o objeto do conhecimento ou da intervenção seria abordado por um único universo disciplinar (UD), o que determinaria uma única dimensão da realidade e um único domínio lingüístico (não podemos nos esquecer de que a ciência é, essencialmente, a constituição de discursos). Como resultado desse modo de produção, teríamos um único texto ou discurso (D). Na perspectiva multidisciplinar, teríamos o objeto de interesse abordado por vários universos disciplinares, determinando várias dimensões da realidade, cada uma com seus respectivos domínios lingüísticos, organizados por um coordenador (C). Como resultado desse modo de produção, teríamos tantos textos quanto universos disciplinares. A perspectiva interdisciplinar, por sua vez, assemelha-se à situação multidisciplinar, só que, agora, com integração dos respectivos domínios lingüísticos de cada disciplina. Essa integração, segundo o autor, seria estimulada pela existência de uma temática comum a todas as disciplinas, segundo a qual deverão abordar o objeto. Como resultado, teríamos tantos textos ou discursos quanto universos disciplinares, porém cada um desses refletiria parte da realidade com o domínio lingüístico 
das outras disciplinas, indicando ter havido cooperação e coordenação entre as disciplinas. Finalmente, a perspectiva transdiciplinar seria caracterizada por um único domínio lingüístico, com base na identificação de zonas de permeabilidade epistêmica entre as disciplinas e pelo foco comum no objeto. Como resultado, teríamos um único texto ou discurso, refletindo a multidimensionalidade da realidade. Nesse caso, a cooperação e coordenação entre as disciplinas visa justamente a transcendê-las.

A pretensão de transcender os espaços estritamente disciplinares coloca a transdisciplinaridade muito além do que seria aceitável por parte dos conselhos de classe e outros reguladores formais das profissões da saúde. Além disso, os profissionais de saúde em geral não explicitam a intenção de estabelecer uma forma de relação entre disciplinas e saberes nos moldes do que se entende por transdisciplinaridade. Por isso, ainda que consideremos esse conceito particularmente instigante e promissor, a noção de transdisciplinaridade seria pouco apropriada neste texto para nosso propósito de correlacionar as diferentes formas de interação disciplinar e seus desdobramentos nas práticas dos profissionais e dos serviços de saúde, conforme discutiremos em mais detalhes no terceiro tópico. Antes, porém, avancemos um pouco mais em relação a questões específicas da interdisciplinaridade.

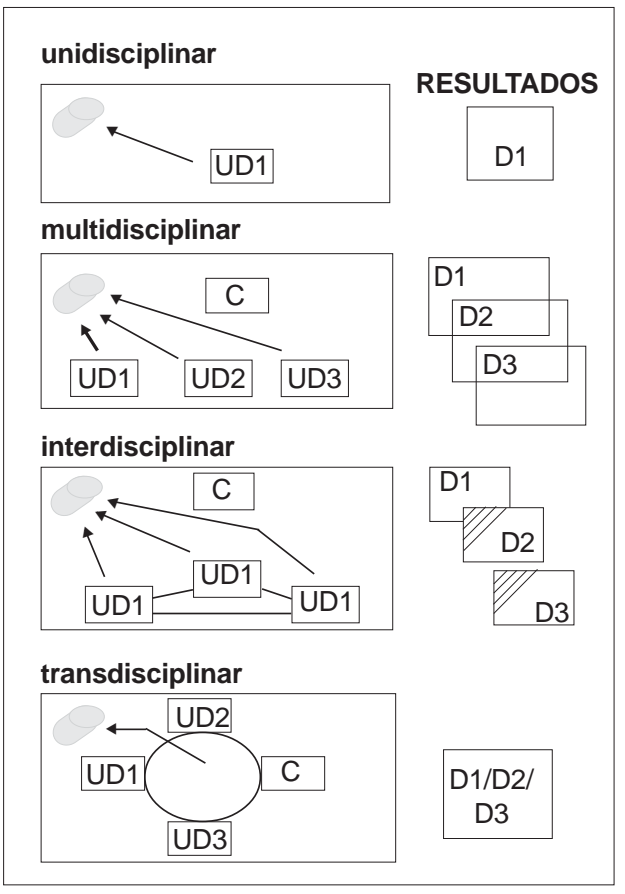

Figura 2. Os modos de produção do conhecimento (adaptado de Silva, 2001, p.6) 


\section{Interdisciplinaridade como mediação}

Alguns autores (Jantsch \& Bianchetti, 2000) criticam a concepção idealista $e$ a-histórica de interdisciplinaridade, que identificam em autores como Japiassu (1976) e Fazenda (2001). Ressaltam que tanto a disciplinaridade como a interdisciplinaridade são construções históricas e produto de tensões entre o sujeito pensante $e$ as condições materiais e objetivas que o cercam $e$ que, inexoravelmente, interferem nessas produções e elaborações. Desse modo, as relações entre disciplinas não poderiam ser reduzidas a criações oriundas de um sujeito abstrato inserido tão-somente no mundo das idéias e apartado de seu objeto.

Para Jantsch (2000), a concepção a-histórica de interdisciplinaridade, predominante no Brasil, levaria a equívocos, tais como: a idéia quase religiosa de pandisciplinaridade, buscando o retorno a uma totalidade "holística" perdida; a postura de condenação moralizadora da especialização, que chega a ser considerada como uma patologia ou câncer do saber e da ciência (Japiassu, 1976), devendo ser extirpada. Segundo Jantsch \& Bianchetti (2000), outro equívoco seria a idéia de que o estabelecimento de parceria entre indivíduos seria suficiente para a superação dessa fragmentação, originando a ilusão de que o distanciamento disciplinar seria fruto da inércia ou má vontade de certos profissionais ou de corporações.

Enfim, para os críticos das postulações de Japiassu e Fazenda, a unidade entre sujeito e objeto foi rompida desde que os homens passaram a pensar em termos formais, causando a disjuntiva fundamental entre homem $e$ natureza (Etges apud Jantsch, 2000), e a interdisciplinaridade viria a cumprir um papel de mediadora entre as diferentes disciplinas, estabelecendo canais de intercomunicações, mas sem a pretensão de constituir-se em novo patamar ou, mesmo, em nova área da ciência.

Para o autor,
A interdisciplinaridade, enquanto princípio mediador entre as diferentes disciplinas, não poderá jamais ser elemento de redução a um denominador comum, mas elemento teórico-metodológico da diferença $e$ da criatividade. A interdisciplinaridade é o princípio da máxima exploração das potencialidades de cada ciência, da compreensão dos seus limites, mas, acima de tudo, é o princípio da diversidade e da criatividade. (Etges apud Jantsch, 2000, p.14)

Como podemos perceber, são muitos os determinantes e as utilizações possíveis em torno do conceito de interdisciplinaridade. Certamente, só temos a ganhar com a consideração dos fatores sociohistóricos que o condicionam e com o esclarecimento dos diferentes usos que podemos fazer desse conceito. Nesse sentido, as críticas levantadas por Jantsch \& Bianchetti (2000) não levam ao impasse, mas, ao contrário, contribuem para o avanço na compreensão e eventual operacionalização do conceito ao apontar algumas de suas lacunas.

Do nosso ponto de vista, a interdisciplinaridade assume grande importância na medida em que identifica e nomeia uma mediação possível 
entre saberes e competências e garante a convivência criativa com as diferenças. Além da função de mediador, o conceito de interdisciplinaridade vem apontar a insuficiência dos diversos campos disciplinares, abrindo caminhos e legitimando o tráfego de sujeitos concretos e de conceitos e métodos entre as diferentes áreas do conhecimento. Assim sendo, a interdisciplinaridade representa uma ferramenta fundamental na grande oficina de produção que se constitui a ciência, não devendo ser tomada como um fim em si mesmo ou uma nova ciência a ser constituída. Ferramenta conceitual, cuja função como tal só se realizará à medida que sua inserção epistemológica criar pontes com as práticas concretas, conforme discutiremos a seguir.

\section{Integração versus diferenciação: uma questão da interprofissionalidade}

Há relativo consenso em torno da necessidade de mais integração entre disciplinas, saberes e práticas, sendo que o desafio do desenvolvimento interdisciplinar há muito alcançou o terreno operacional, tornando-se tema recorrente no discurso dos profissionais e suas equipes. Não é incomum ouvirmos relatos dos trabalhadores sobre a irracionalidade advinda justamente do excesso de racionalização e compartimentalização das práticas profissionais em saúde. Por essa razão e considerando que o presente estudo se realiza no âmbito da saúde coletiva, caberia indagar sobre que conseqüências poderíamos extrair da discussão sobre integração disciplinar no que tange à organização e qualificação dos serviços de saúde e suas práticas.

Em primeiro lugar, faz-se necessário distinguir os planos disciplinares e profissionais. No presente texto, utilizaremos o sufixo "disciplinar" quando nos referirmos ao desenvolvimento do conhecimento em sua vertente epistemológica e "profissional", às práticas concretas, conforme proposto por D'Amour (1997). Assim, pluri e interdisciplinaridade são termos relativos a conceitos e teorias voltados para a compreensão de fenômenos, enquanto pluri e interprofissionalidade dizem respeito a práticas voltadas para a solução de problemas empíricos específicos. Ainda que, na prática, seja difícil encontrar tipos "puros" (afinal prática-teoria-prática interagem e se realimentam), essa definição tem valor por distinguir princípios gerais (por exemplo: "interdisciplinaridade") de seus desdobramentos na prática cotidiana dos trabalhadores (por exemplo: "interprofissionalidade"). Em poucas palavras: o sufixo "disciplinar" será sempre relativo ao campo dos saberes, e "profissional" ao das equipes e seus serviços.

Aliás, poderíamos afirmar que a discussão sobre integração de práticas $e$ saberes tem início, de fato, a partir do momento em que se incorpora (ou se tenta incorporar) tais princípios nas práticas das equipes, donde emergirão questões cuja complexidade e teor fomentarão sobremaneira as discussões sobre o tema. Com base nas tentativas de avanço no plano da relação tradicional entre membros de equipes, poderemos identificar as razões pelas quais - a despeito da concordância com os princípios genéricos próintercâmbio - a organização dos serviços mantém-se, geralmente, assentada no paradigma uni ou pluridisciplinar. 
Alguns estudos têm demonstrado que, dentre as diferentes categorias, predomina a tendência em satisfazer aspirações profissionais e manter sua autonomia, em detrimento da colaboração profissional (D'Amour, 1997). Tal postura espelha a própria constituição das profissões, que possuem, em comum, os interesses pragmáticos de garantia de mercado de trabalho. Conforme nos lembram estudos realizados pela sociologia das profissões, o profissionalismo constitui-se na história como estratégia de retenção do conhecimento, buscando torná-lo o mais específico e misterioso possível, permanecendo acessível a poucos e, assim, garantindo reserva de mercado (Machado, 1995).

Por isso, colaboração profissional e profissionalismo constituirão dois lados em constante oposição, ainda que a existência de um dependa da existência do outro. Por um lado, temos a colaboração profissional, que requer ou promove relações e interações nas quais os profissionais poderão colocar à disposição $e$ partilhar seus conhecimentos, especialização, experiência e habilidades entre si, com vistas a proporcionar melhor atenção ao paciente. Essa lógica de colaboração baseia-se em valores humanistas, buscando recolocar profissionais em torno da pessoa, e não ao redor de territórios de especialização. A proposta de trabalho em colaboração interprofissional surge como resposta a diversos impasses "dentre eles, a complexidade dos problemas clínicos "à necessidade de reagrupamento de conhecimentos espalhados, como forma de diminuir a alienação do trabalhador e para evitar a duplicação de cuidados.

Por outro lado, temos o profissionalismo ou lógica profissional, marcado pela delimitação estrita de territórios de cada grupo profissional. Por meio da assimilação de saberes específicos em suas respectivas faculdades e, mais tarde, por meio da vinculação a associações, conselhos de classe e código de ética, um indivíduo passará a compor um grupo exclusivo de profissionais, podendo aplicar conhecimentos abstratos, aprendidos por meio de sua formação, a casos sempre particulares com os quais irá se defrontar em sua lida cotidiana (Machado, 1995). A partir daí, esse mesmo indivíduo passará a ter uma identidade profissional "extremamente valorizada em nossa sociedade", facultando a quem obtém o diploma responder prontamente a perguntas como "o que você é?" ou "o que você faz?", que denotam a importância social dada às profissões e ocupações.

O que vimos afirmando demonstra que abordar o tema da colaboração implica considerar duas forças antagônicas. A primeira, um pólo representado pelas corporações profissionais, pela lógica profissional, que tenta continuamente garantir um mercado definido e inviolável e expandir territórios, aumentar sua autonomia e elevar seu grau de dominação e controle sobre outras categorias. O outro pólo é representado pela lógica da colaboração profissional, apontando para a necessidade de colocar em comum e partilhar conhecimentos, especialidades, experiências, habilidades e, até, a intersubjetividade.

Dessa forma, transpor a discussão da interdisciplinaridade para o campo das práticas em saúde é enfrentar o antagonismo entre o modelo da lógica profissional e o modelo de colaboração interprofissional ou, mais resumidamente, entre a diferenciação (que buscamos ativamente pela formação profissional) e a integração (requerida pela colaboração interprofissional e condição para qualificação da clínica). Assim, trabalhar em favor da colaboração implica reconhecer que o sujeito busca conquistar um 
status diferenciado por meio da formação profissional. Por isso, o desafio de promover a colaboração não deve ser levado à frente negando uma especificidade duramente alcançada, mas tentando estabelecer pontes entre posições inicialmente antagônicas.

Conforme discutido por Almeida Filho (1997), no limite, a interdisciplinaridade ou a colaboração profissional não se efetiva por meio de princípios ou de intenções genéricas desenvolvidas em textos de pesquisadores bem-intencionados. A troca efetiva e colaboração entre disciplinas e profissões somente serão possíveis pela ação de agentes concretos que, por meio de sua mentecorpo, irão ou não consubstanciar práticas mais ou menos integradas. Como ilustrado pelo autor, é somente mediante a concretude dos aparelhos cognitivos de indivíduos que transitem em diferentes áreas que ocorrerão os diferentes graus de interação e colaboração entre disciplinas e profissões (Almeida Filho, 1997).

Sobre esse agente concreto incidirão forças diferentes e simultâneas, tendentes mais a um ou outro dos dois pólos que vimos discutindo. Assim, sobre um dado profissional agirão vetores que tendem a conformar suas ações para uma prática mais ou menos interligada, para um perfil de mais diferenciação ou de integração. Esses vetores são simultâneos e sua predominância pode variar ao longo do tempo, ao longo de uma situação vivida pelo profissional e sofrer influências da organização institucional e outras estruturas maiores $e$ englobantes. No Quadro 1, apresentamos uma síntese da multideterminação envolvida nas lógicas da colaboração e da profissionalização.

Quadro 1. Elementos determinantes das lógicas da profissionalização e da colaboração interprofissional*

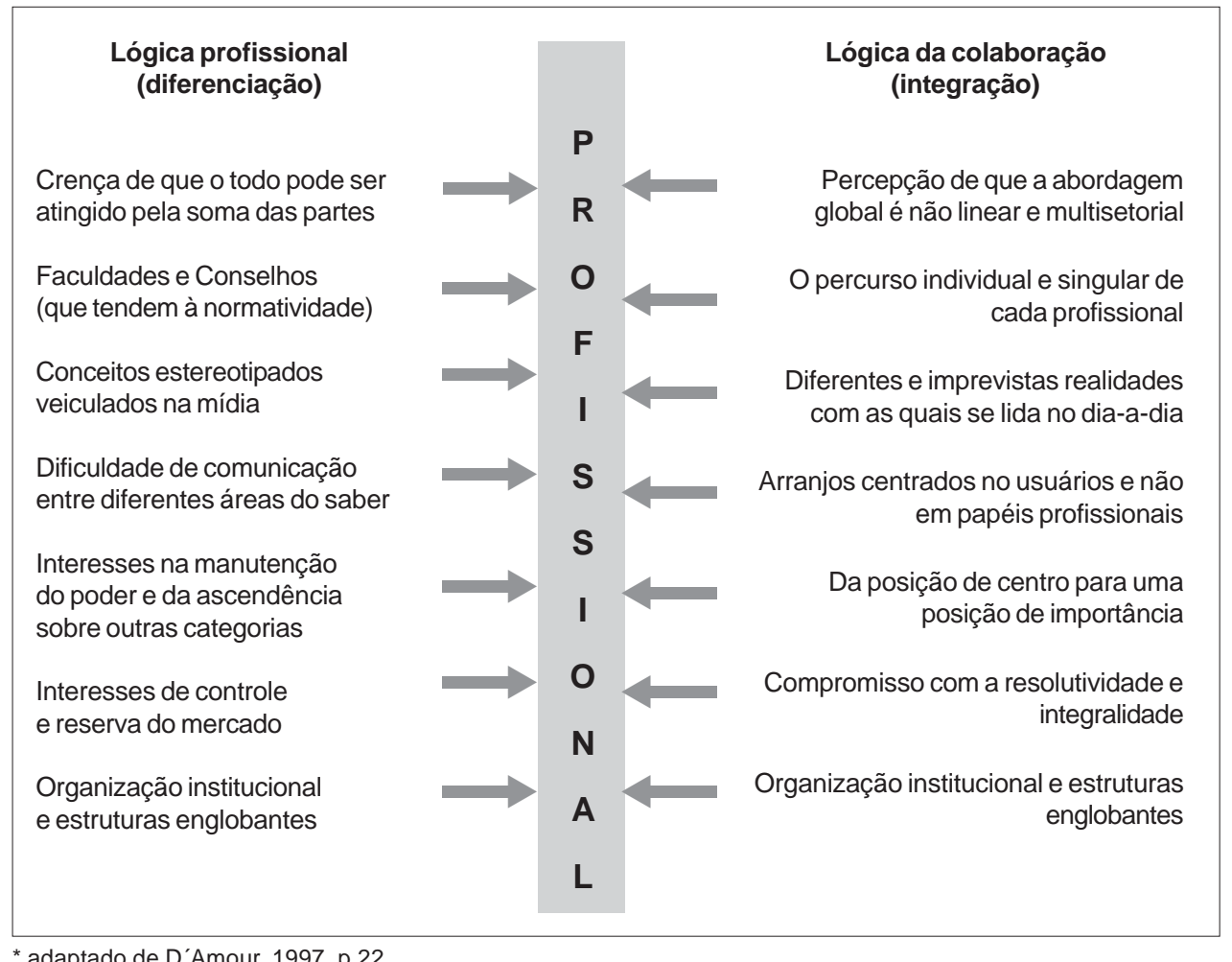


Devemos observar que, à medida que aumenta o grau de colaboração profissional, decresce a autonomia individual, uma vez que a condução de planos terapêuticos passa a ser negociada entre os seus integrantes, o que pode ser particularmente difícil para alguns sujeitos. Por outro lado, esse aumento de colaboração profissional expande a troca na tomada de decisões clínicas e a integralidade dos cuidados, permitindo o aumento de autonomia da equipe como um todo frente aos problemas por ela enfrentados.

Não devemos nos esquecer de que colaboração interprofissional é, essencialmente, co-laboração, ou seja, é trabalho com e entre muitos, portanto ação em equipe - o que não é algo simples. Para o funcionamento efetivo em equipe, baseado em profunda colaboração interprofissional, a deliberada vontade e orientação de seus integrantes é necessária, mas não suficiente. É fundamental a instauração de ambiente democrático e de estruturas e mecanismos institucionais que garantam o surgimento, desenvolvimento e manutenção de espaços intra-equipes que permitam o florescimento de práticas fundadas na cooperação entre saberes e ações. No quinto tópico, discutiremos um modelo de atenção voltado para a garantia, entre outras coisas, de um trabalho em saúde calcado na colaboração interprofissional. Vejamos, previamente, dois importantes conceitos que podem auxiliar na transposição do que vimos discutindo para a prática.

\section{Integração e diferenciação:}

entre núcleo e campo de competência e responsabilidade

Os conceitos de núcleo e campo de competência e responsabilidade são bastante eficazes para a análise e compreensão de ações e trânsitos entre especificidades que diferenciam e caracterizam os profissionais (núcleos) e iniciativas importantes, mas que não pertencem a nenhuma área em particular requerendo, sobretudo, colaboração entre elas (campo). Trata-se de um importante conceito-ferramenta elaborado por Campos (1997) para estabelecer a compreensão de que existem atribuições específicas de determinada categoria profissional - que o autor chamou de núcleo de competência e responsabilidade - e demandas que extrapolam essas atribuições estabelecidas - que o autor denominou de campo de competência e responsabilidade.

Assim é que núcleo diz respeito aos elementos de singularidade que definem a identidade de cada profissional ou especialista e campo seria constituído por responsabilidades e saberes comuns ou convergentes a várias profissões ou especialidades:

(...) núcleo demarcaria a identidade de uma área de saber e de prática profissional; e o campo, um espaço de limites imprecisos onde cada disciplina ou profissão buscariam, em outras, apoio para cumprir suas tarefas teóricas e práticas. (Campos, 1997, p.249)

O núcleo é facilmente percebido por meio dos ditames dos conselhos profissionais, das disciplinas específicas de cada categoria e que conformam um dado profissional. O campo é mais aberto, sendo definido com base no 
contexto em que operam certas categorias de profissionais. Um exemplo dado pelo autor é o de um especialista em gineco-obstetrícia, que teria como núcleo o conjunto de saberes e práticas relativos à saúde da mulher, e como campo, noções de clínica geral, fundamentos da relação profissionalpaciente, organização de programas, educação em saúde etc. (Campos, 1997). A constituição e finalidade de um serviço determinarão maior ou menor quantidade de ações de campo ou de núcleo: em uma UTI, por exemplo, predominarão ações ligadas aos núcleos, enquanto em certas ações de uma equipe do PSF podem prevalecer ações ligadas ao campo.

Esses dois conceitos ajudam a compreender e superar os impasses oriundos de um certo borramento das fronteiras entre as categorias profissionais, iluminando a penumbra constituída por demandas que permanecem à margem por não serem contempladas pelos núcleos de cada profissão - mas que, nem por isso, deixam de ser importantes e eventualmente urgentes. Os conceitos de campo e núcleo de competência e responsabilidade fornecem também importantes subsídios para a análise, compreensão e operacionalização de intervenções no âmbito da inter e transdisciplinaridade. Esses conceitos permitem, simultaneamente, a consideração das especificidades que conformam cada categoria profissional ou área do saber (núcleos) e suas articulações possíveis dentro dos espaços definidos por demandas complexas, que extrapolam as fronteiras estabelecidas pelos núcleos de determinadas profissões ou áreas do conhecimento, constituindo campos (Figura 3).

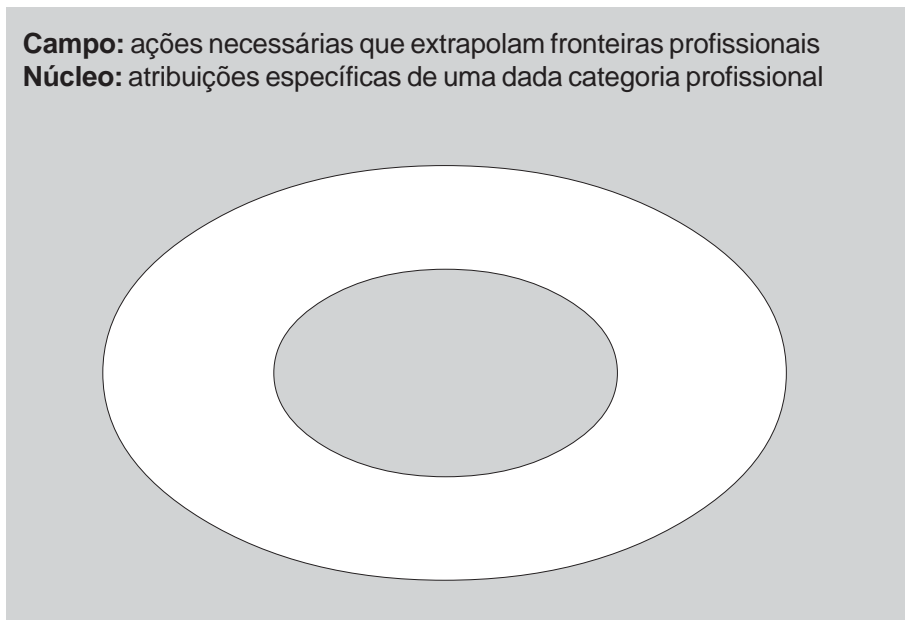

Figura 3. Equipe de referência: trânsito entre campo e núcleo.

Como podemos perceber, as atividades ligadas ao campo são essencialmente interdisciplinares e requerem elevado grau de interprofissionalidade, enquanto aquelas ligadas ao núcleo são voltadas para atribuições típicas e 
exclusivas de determinada categoria profissional. A compreensão, por parte dos profissionais, desses dois conceitos, permite mais clareza do que pode ser partilhado e a certeza de que a colaboração com seus pares não implicará perda de sua identidade ou núcleo profissional.

Pierre Bordieu (1992), sociólogo francês, trabalhou de maneira especial a noção de "campo". No entanto, o uso dos conceitos de campo e núcleo de competência e responsabilidade, realizado por Campos (1997), não é análogo ao realizado por Bordieu.

Para Bordieu, a passagem do campo ao corpus é uma passagem de um certo senso comum ao saber dos especialistas. Passagem que implica o controle (e a regulação) de certas técnicas, e que se faz possível por meio de uma expropriação dos leigos constituídos nesse mesmo processo. (Onocko Campos, 2003, p.75)

De maneira diferente, os conceitos de campo e núcleo que vimos apresentando nesse tópico sustentam a instituição de novas relações entre saberes e práticas no interior de um campo profissional constituído, com vistas a ampliar a relação de especialistas com saberes $e$ procedimentos estabelecidos. (p.77)

\section{Equipes de referência:}

um modelo tecnoassistencial favorecendo a colaboração interprofissional

As peculiaridades do setor saúde o tornam especialmente interessante no estudo das formas de colaboração profissional, uma vez que apresenta grande especialização em categorias e procedimentos e, ao mesmo tempo, vem sendo pressionado para diminuir a fragmentação de suas abordagens aos pacientes, seja por razões de eficácia ou, mesmo, de equacionamento de custos. Trata-se, ainda, de um setor no qual prevalecem profissionais liberais de várias formações, que obedecem (e, freqüentemente, privilegiam) orientações exteriores à organização, como aquelas provenientes dos conselhos de classe. Além disso, os membros das equipes de saúde atuam sobre problemas de extrema complexidade, realizando tarefas interdependentes e sobre as quais possuem controle relativo e cujos desdobramentos são sempre incertos, já que condicionados por vários fatores ( $D^{\prime}$ Amour, 1997). Some-se a isso o fato de que certas ações exigem trocas intersubjetivas (como na saúde mental, por exemplo), e alguns dos problemas sobre os quais agem os profissionais da saúde podem eventualmente acometê-los diretamente, gerando várias formas de resistência e/ou identificações (Onocko Campos, 2003).

Por seu lado, o contexto do SUS tem como uma de suas diretrizes a integralidade, caracterizada pela oferta de atenção às necessidades de promoção, prevenção, tratamento e reabilitação de um dado indivíduo ou comunidade, considerando seu contexto social. A busca do atendimento integral tem, como grande desafio, a reestruturação dos estabelecimentos $e$ das organizações do setor saúde, o que deverá ocorrer tanto por meio da 
organização e articulação desses serviços entre si quanto na reformulação das práticas dos profissionais de saúde em suas respectivas equipes (Aguilera Campos, 2003). Dentro do foco da presente discussão, podemos afirmar que a reorganização do trabalho interprofissional dentro das equipes dos serviços de saúde do SUS é condição necessária para a conquista da integralidade, na medida em que pode possibilitar a detecção de necessidades e o provimento de cuidados de maneira mais completa $e$ ampliada aos usuários (Pinheiro \& Mattos, 2006).

O que vimos afirmando nos dois últimos parágrafos traça um cenário de complexidade: a implementação da colaboração profissional em um setor constituído por várias especialidades em contínua superespecialização, regidas por órgãos influentes e externos aos serviços e cujo objeto de trabalho (sofrimento e morte) pode levar os trabalhadores a se protegerem de várias formas, inclusive por detrás de normas, protocolos e outros modos de cristalização de papéis. Por sua vez, o sus carece de dispositivos que implementem a colaboração profissional de modo a honrar um dos seus princípios basais, a integralidade.

É nesse ponto que se coloca o desafio: como estruturar equipes de saúde de modo a garantir condições para o fluxo de trocas e inter-relações profissionais, de saberes e de gestão compartilhada, como vimos discutindo até aqui, de modo a aumentar o coeficiente de integralidade? Como articular as diferentes iniciativas dos profissionais tendo o paciente como centro? Aqui encontramos, ao mesmo tempo, o ponto de tensão e o elo que nos interessa: a interface e os desdobramentos possíveis entre os conceitos de interdisciplinaridade e interprofissionalidade para a qualificação da condução clínica dentro do SUS. A proposta de Campos (1999), relativa à organização do trabalho em saúde, estruturada em equipes de referência, nos parece especialmente adequada como forma de traduzir, estruturar $e$ possibilitar - numa palavra, viabilizar no âmbito das equipes, o ideário da interdisciplinaridade. Nessa proposta, o autor consegue articular princípios gerais a modos específicos de funcionamento organizacional, ao mesmo tempo em que cria mecanismos para garantir aumento de poder e graus de co-gestão aos membros dessa mesma equipe.

Para Campos (1999), o arranjo organizacional das equipes de referência ${ }^{2}$ tem, nas noções de vínculo terapêutico, interdisciplinaridade e gestão

2 A definição de "equipe de referência" será detalhada a seguir e não deve ser confundida com "serviços $e$ equipamentos de referência", utilizados para apoio às demais equipes na clínica cotidiana. colegiada, seus pilares centrais na busca de superação do modelo médico hegemônico e de fragmentação das ações em saúde. Em outro estudo, completa:

A equipe de referência é composta por um conjunto de profissionais considerados essenciais para a condução de problemas de saúde dentro de certo campo de conhecimento. Dentro dessa lógica, a equipe de referência é composta por distintos especialistas e profissionais encarregados de intervir sobre um mesmo objeto - problema de saúde -, buscando atingir objetivos comuns e sendo responsáveis pela realização de um conjunto de tarefas, ainda que operando com diversos modos de intervenção. O máximo de poder delegado à equipe interdisciplinar.

(Domitti \& Campos, 2005, p.4) 
Segundo essa proposta, os serviços seriam organizados com base em equipes compostas por profissionais de diferentes categorias, de acordo com as características do problema enfrentado, tendo uma clientela predefinida. Por exemplo, um centro de reabilitação poderia ter equipes de referência compostas por: profissional de enfermagem, fisioterapeuta, terapeuta ocupacional, médico e assistente social. Havendo número de profissionais suficiente, poderia ter duas, três ou mais dessas equipes, cada uma delas tendo como características: a) inclusão de profissionais de categorias distintas; b) definição de clientela adscrita, permitindo o acompanhamento longitudinal e formação de vínculo entre trabalhadores e usuários; c) formulação de projetos terapêuticos singulares para os casos mais complexos e/ou de maior vulnerabilidade; d) poder de decisão no que concerne ao trabalho da equipe (algum grau de co-gestão); e) receber ou realizar apoio profissional especializado quando necessário (apoio matricial).

Esse modelo vem sendo utilizado em vários serviços de diferentes municípios. De nossa parte, com base na experiência de gestão de equipes de saúde, pudemos constatar a potência do modelo de equipes de referência para qualificar a atenção ao usuário e possibilitar verdadeira interação técnica e subjetiva entre os componentes dessas equipes (Miranda \& Furtado, 2006; Furtado, 2001). No entanto, tal mudança envolve o enfrentamento de vários obstáculos, como: a organização tradicional das instituições tendentes à manutenção do status quo, o excesso de demanda $e$ carência de recursos, a disputa de poder entre níveis da instituição $e$ corporações profissionais, dentre outros (Domitti \& Campos, 2005).

Deve-se notar que esse modelo realiza um recorte diferente ao agregar distintas categorias profissionais em torno dos casos a serem atendidos, superando a organização dos serviços segundo departamentos (de enfermagem, psicologia etc.), que baseiam suas interações em "interconsultas". Essas equipes de referência constituiriam a menor unidade organizacional e administrativa dos serviços nos quais são implementadas, ou seja, instituições assim organizadas não mais reconheceriam posturas individuais ou estritamente corporativas. Esse arranjo desloca o poder das profissões e corporações de especialistas e reforça o poder de gestão da equipe interdisciplinar (Domitti \& Campos, 2005).

Nesse cenário, a construção do projeto terapêutico se dá mediante várias perspectivas e com base na interação entre o paciente e seus profissionais de referência, nas interlocuções desses últimos entre si e com outros grupos, como: família, instituições de saúde, setores culturais e socioeducacionais, etc. É função básica desse dispositivo garantir a continuidade do tratamento, evitando-se a perda do paciente nas teias conhecidas $e$ descontextualizadas constituídas pelos "encaminhamentos". Seu sucesso está fundamentalmente ligado à ampliação da clínica (Campos, 2003), o que significa garantir que os respectivos projetos terapêuticos considerem o seguimento dos pacientes tanto no plano subjetivo quanto no social, familiar, laboral, dentre outros, porém sempre articulados pelos profissionais de referência.

Naturalmente, deverá ser garantido espaço sistemático de encontro entre os integrantes dessa equipe, de modo a discutir os casos novos, avaliar os 
pacientes em acompanhamento e definir ações que se façam necessárias. A tarefa da equipe de referência constitui-se em trabalho com e entre muitos, por isso o modelo de gestão e outras formas de organização do serviço deverão garantir à equipe a possibilidade de análise de seus inevitáveis conflitos, estabelecendo arranjos e dispositivos institucionais que possibilitem o convívio com a diferença -e apesar dela. É necessária a existência de espaços de supervisão clínico-institucional, oficinas de planejamento, discussões grupais e demais iniciativas que permitam emergir e circular a palavra, considerando os conflitos e os afetos inerentes à lida intensiva com pacientes graves (Onocko Campos, 2003). Afinal, a interprofissionalidade pressupõe maior freqüência e intensidade de relações $e$ a superação de contatos protegidos por normas e protocolos, o que exige mais cuidado $e$ análise constante das diferentes interações por parte dos coordenadores do serviço.

Além de ser um arranjo destinado a concretizar e potencializar o compartilhamento de práticas e saberes, a organização de serviços segundo a proposta de equipes de referência permite a superação de relações especulares entre terapeuta e paciente (sobretudo, quando se trata de doenças crônicas, com acompanhamento de longo prazo), e o recebimento de apoio de um dado profissional, por parte dos outros colegas da equipe de referência, quando se lidam com casos especialmente difíceis. Um cuidado constante a ser tomado é de que a equipe de referência ocupe um lugar de importância, mas não de centro, na relação com o paciente - este, sim, deve ser o foco das ações e reflexões da equipe -. e que se garantam trânsitos $e$ trocas entre essas equipes em um mesmo serviço, evitando-se o enclausuramento e eventuais disputas entre elas.

\section{Conclusão}

A interdisciplinaridade e seu correlato na prática dos serviços, a interprofissionalidade, constituem categorias importantes para analisarmos algumas limitações importantes das práticas contemporâneas de saúde. Dentre elas, destacamos a baixa correlação entre superespecialização $e$ efetividade dos serviços de saúde, ou seja, elas nos ajudam a buscar respostas sobre por que os investimentos financeiros e de produção intelectual não geram equivalente qualificação e resolutividade dos serviços à população, o que parece sugerir a necessidade de aumentar a capilarização e circulação colateral entre as profissões, e não apenas o seu desenvolvimento e aprofundamento solitário.

Por outro lado, já se disse que a idéia de interação disciplinar e profissional só é possível e tem sentido na prática (Almeida Filho, 1997). Por essa razão, o grande desafio desta discussão é a tradução e implementação de seus princípios em serviços concretos, o que poderá, enfim, gerar ganhos reais aos usuários e a identificação de novas questões que mereçam a atenção dos interessados nesse tema.

No entanto, essas mudanças só superarão seus obstáculos na medida em que não se basearem em concepções ingênuas, como a da unidade de um saber perdido que "naturalmente" anseia e converge para uma nova 
integração, retomando um passado de unidade (Jantsch \& Biachetti, 2000). São muitas as determinações históricas que levaram à criação das diferentes disciplinas $e$ atividades profissionais; $e$ a discussão da interdisciplinaridade $e$ interprofissionalidade agrega valor somente na medida em que possibilita aos profissionais compreenderem essas mesmas determinações históricas, autorizando-se a criar novos modos de vivência e convivência institucional, aumentando gradativamente seus gradientes de co-gestão.

No que concerne ao SUS, seria importante o acompanhamento rigoroso $e$ a avaliação sistemática das várias experiências em curso, que vêm funcionando segundo a lógica de equipes de referência. Em várias cidades brasileiras existem iniciativas em atenção básica, saúde mental e hospitais públicos, dentre outros, que vêm relatando êxitos mediante a reorganização do modus operandi de suas equipes, com base em um modelo tecnoassistencial que favorece a colaboração interprofissional.

Referências

AGUILERA CAMPOS, C.E. O desafio da integralidade segundo as perspectivas da vigilância da saúde e da saúde da família. Ciênc. Saúde Coletiva, v.8, n.2, p.569-84, 2003.

ALMEIDA FILHO, N. Transdisciplinaridade e saúde coletiva. Ciênc. Saúde Coletiva, v.2, n.1/2, p.5-20, 1997.

BOURDIEU, P. A economia das trocas simbólicas. São Paulo: Perspectiva, 1992.

CAMPOS, G.W.S. (Org.). Saúde Paidéia. São Paulo: Hucitec, 2003.

. Equipes de referência e apoio especializado matricial: um ensaio sobre a reorganização do trabalho em saúde. Ciênc. Saúde Coletiva, v.4, n.2, p.393-403, 1999.

. Subjetividade e administração de pessoal: considerações sobre modos de gerenciar o trabalho em equipes e saúde. In: MERHY, E.E.; ONOCKO CAMPOS, R. (Orgs.). Agir em saúde. São Paulo: Hucitec, 1997. p.229-66.

D'AMOUR, D. Structuration de la collaboration interprofessionelle dans les services de santé de première ligne au Québec. 1997. Tese (Doutorado) - Université de Montreal, Montreal, Canadá.

DOMITTI, A.C.P.; CAMPOS, G.W.S. Um possível diálogo com a teoria a partir das práticas de apoio especializado matricial na atenção básica de saúde. Campinas: Departamento de Medicina Preventiva e Social, FCM/Unicamp, 2005. Mimeogr.

FAZENDA, I. (Org.) Interdisciplinaridade: dicionário em construção. São Paulo: Cortez, 2002. . Interdisciplinaridade: história, teoria e pesquisa. Campinas: Papirus, 2001.

FURTADO, J.P. Responsabilização e vínculo no tratamento de pacientes cronificados: da Unidade de Reabilitação de Moradores ao Caps Estação. In: ARARI, A.; VALENTINI, W. (Orgs.). A reforma psiquiátrica no cotidiano. São Paulo: Hucitec, 2001. p.32-48.

GUSDORF, G. Réflexions sur l'interdisciplinarité. Bull. Psychol., v.43, n.397, p.869-85, 1967. 
JANTSHC, A.P. Interdisciplinaridade: para além da filosofia do sujeito. In: JANTSCH, A. P.; BIANCHETTI, L. (Orgs.). Interdisciplinaridade: para além da filosofia do sujeito. Petrópolis: Vozes, 2000, p.113-44.

JANTSCH, A.P.; BIANCHETTI, L. Interdisciplinaridade: para além da filosofia do sujeito. Petrópolis: Vozes, 2000.

JAPIASSU, H. Interdisciplinaridade e patologia do saber. Rio de Janeiro: Imago, 1976.

MACHADO, M.H. Sociologia das profissões: uma contribuição ao debate teórico. In: (Org.).

Profissões de saúde: uma abordagem sociológica. Rio de Janeiro: Fiocruz, 1995. p.82-107.

MIRANDA, L.; FURTADO, J.P. O dispositivo 'técnico' de referência nos equipamentos substitutivos em saúde mental e o uso da psicanálise Winnicottiana. Rev. Latinoam. Psicopatol. Fund., 2006. Aprovado para publicação.

MORIN, E. A cabeça bem-feita: repensar a reforma e reformar o pensamento. Rio de Janeiro: Bertrand Brasil, 1999.

NUNES, E.D. A questão da interdisciplinaridade no estudo da saúde coletiva e o papel das ciências sociais. In: CANESQUI, A. M. (Org.). Dilemas e desafios das ciências sociais na saúde coletiva. São Paulo: Hucitec-Abrasco, 1995. p.95-113.

ONOCKO CAMPOS, R. A gestão: espaço de intervenção, análise e especificidades técnicas. In: CAMPOS, G.W.S. (Org.). Saúde Paidéia. São Paulo: Hucitec, 2003. p.122-52.

PINHEIRO, R.; MATOS, R.A. Os sentidos da integralidade na atenção e no cuidado à saúde. Rio de Janeiro: IMS/UERJ, CEPESC, ABRASCO, 2006.

RANDOM, M. (Org.). O pensamento transdisciplinar e o real. São Paulo: Triom, 2000.

SILVA, D.J. O paradigma transdisciplinar: uma perspectiva metodológica para a pesquisa ambiental. Disponível em: <http://www.ufrj.br/leptrans/link/pesquisaambiental. pdf>. Acesso em: 25 abr. 2006.

FURTADO, J.P. Equipos de referencia: arreglo institucional para potencializar la colaboración entre disciplinas y profesiones. Interface - Comunic., Saúde, Educ., v.11, n.22, p.239-55, mai/ago 2007.

La necesidad de mayor colaboración entre disciplinas y profesiones es frecuentemente resaltada en diferentes textos y apuntada como posible solución para diversos impases y cuestiones vividas por los equipos que actúan en programas y servicios de los sectores salud y educación. Sin embargo, la discusión sobre la interacción disciplinar y profesional ha carecido de avances en relación con lo que fue introducido en Brasil a partir de los años setenta del pasado siglo. Por otro lado, el sistema de salud en Brasil necesita de propuestas que efectivamente operen la integración entre saberes y prácticas en el ámbito de los servicios. En el presente artículo, presentamos algunas críticas a la concepción dominante de colaboración interdisciplinaria e interprofesional y apuntamos la organización de servicios con base en equipos de referencia como forma de estimular y aumentar la colaboración entre disciplinas y profesiones.

PALABRAS CLAVE: Interdisciplinario y salud. Servicios de salud. Organización y administración de servicios. Salud colectiva. Planificación en salud. 


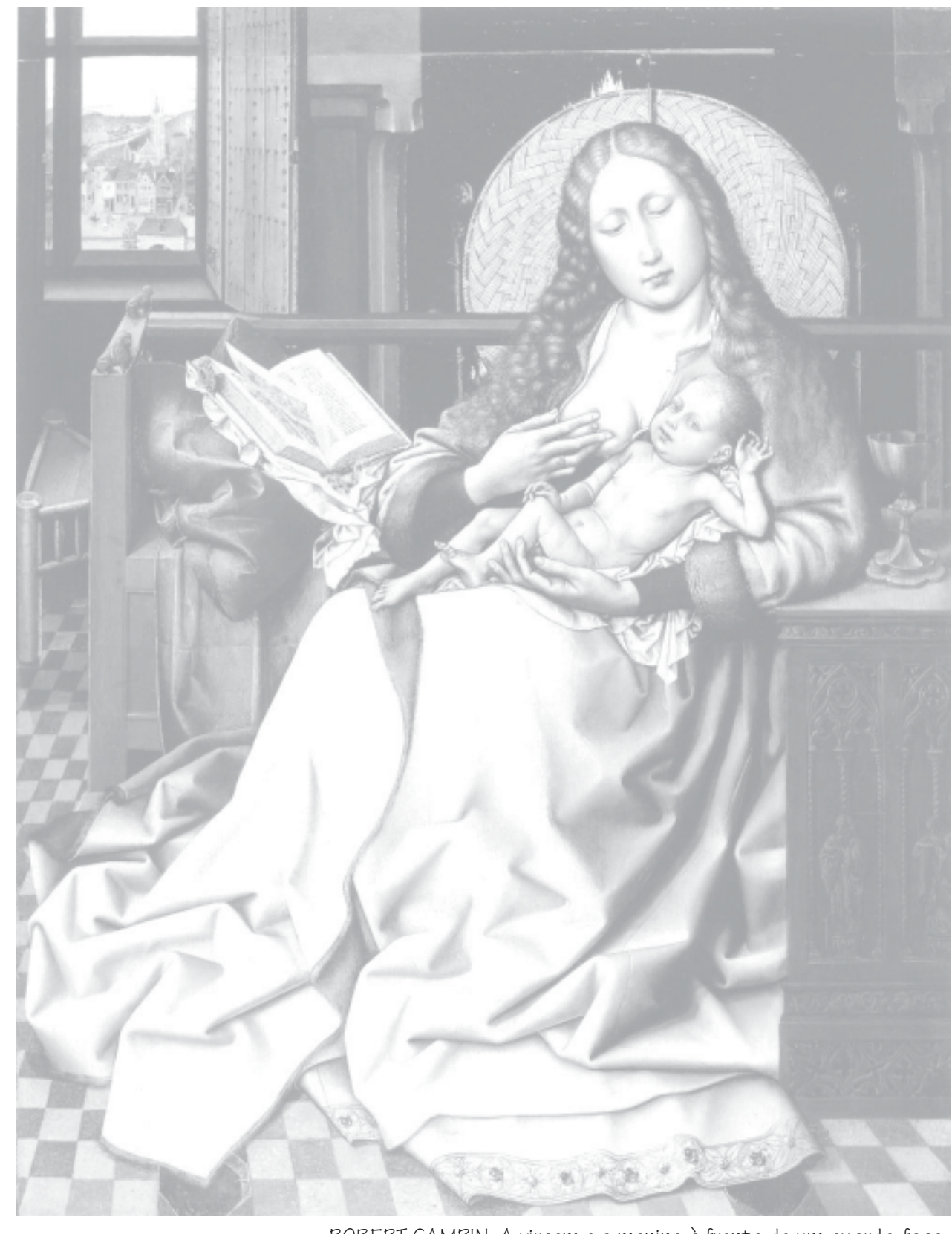

ROBERT CAMPIN, A virgem e o menino à frente de um guarda-fogo 